\title{
Investigation of ultrasonic treatment of wastewater from iron compounds
}

\author{
Liliia Frolova ${ }^{1, *}$, Mykola Shapa ${ }^{2}$, Tetiana Butyrina ${ }^{1}$, Mariia Savchenko ${ }^{1}$, and Tetiana \\ Hrydnieva $^{1}$ \\ ${ }^{1}$ Ukrainian State University of Chemical Technology, 49005, Dnipro, Haharina Ave., 8, Ukraine \\ ${ }^{2}$ Regional Institute of Public Administration, National Academy of Public Administration, Office of \\ the President of Ukraine, 49044, Dnipro, Hoholia Str., 29, Ukraine
}

\begin{abstract}
The high level of wastewater pollution in the mining and metallurgical industries by compounds of heavy metals, including iron, enhances their migration into the environment. Due to the lack of universal high-performance and inexpensive methods of wastewater treatment and purification, the development of new technologies is very relevant. The article discusses the possibility of wastewater treatment by ultrasonic coagulation of iron compounds in a suspended colloidal state. It has been shown that the frequency of ultrasound does not affect the coagulation rate. The concentration of iron compounds in wastewater is inversely proportional to the intensity of ultrasound. It was also found that the dependence of the residual content of iron compounds on the processing time is extreme, which is associated with the formation of agglomerates and their subsequent destruction. The results obtained served as the basis for the development of the technological scheme.
\end{abstract}

\section{Introduction}

At the present stage of development of engineering and technology, the task of treating wastewater containing metal ions (especially iron) in connection with their negative impact on the environment and human health is very relevant [1].

The main source of iron compounds in surface water is the chemical weathering of rocks, accompanied by their mechanical destruction and dissolution. As a result of the interaction of iron ions with mineral and organic substances contained in natural waters, a complex of iron compounds is formed in dissolved, colloidal and suspended states. In addition, significant amounts of iron enter natural waters with wastewater from enterprises in the metallurgical, fuel, mining industries, while mining mineral raw materials.

The increased content of iron compounds in the water gives it a brownish color, an unpleasant metallic taste, thus worsening its organoleptic properties and negatively affecting the human body. Iron overload in the body can lead to heart disease, cancer development [2].

Traditional technologies for wastewater treatment from iron cations, that based on physicochemical methods, have certain disadvantages [1]. Various methods are used to

\footnotetext{
*Corresponding author: 19kozak83@gmail.com
} 
treat wastewater from colloidal particles, including: filtering on membrane filters, ultrafiltration, reverse osmosis, coagulation, electrocoagulation, acoustic coagulation, flotation, and others [1].

Currently, reagent-free water treatment methods are promising. The use of various kinds of physical fields and electric discharges makes it possible to carry out technological processes at significantly lower energy costs due to the complex action of many factors that accompany their appearance (UV radiation, radiolysis, etc.) [3 - 8]. Of particular scientific and practical interest is acoustic cleaning as a promising and economically feasible method. The effect of cavitation on water leads to a change in its physicochemical properties: an increase in $\mathrm{pH}$, electrical conductivity of water, an increase in the number of free ions and active radicals, and molecular structuring and activation $[9,10]$.

The use of ultrasound in water treatment technologies has been studied for many years [11 - 15]. There is still no full explanation of the mechanism of a number of phenomena, despite the results that obtained from researchers in this field.

The authors of $[7,16]$ attribute the influence of high-power ultrasound not in the interaction of acoustic waves with matter at the molecular or atomic level. Cavitation generates unique synthesis conditions - high temperatures and pressures, as well as huge heating and cooling rates. Moreover, a high concentration of various radicals built from chemically active liquid atoms is generated. In [17], the possibility of electrochemical processes occurring due to polarization of the phase distribution boundary during ultrasonic treatment of aqueous solutions is considered, the electric current arising is the cause of the majority of the ongoing processes.

The purpose of this work is to study the possibility of tertiary treatment of wastewater from colloidal particles of iron compounds. A preliminary analysis of water samples taken at the discharge site showed that the concentration of total iron in the discharged water is $0.013-0.084 \mathrm{~g} / \mathrm{l}$, and in some cases $0.6 \mathrm{~g} / \mathrm{l}$.

\section{Experimental}

The main object of research in the work is treated wastewater metallurgical plant EVRAZ DMZ (Dnipro), which containing in its composition iron compounds in suspended colloidal state. Wastewater is taken directly from the outlet at the enterprise using a sampler of simple design [18].

Determination of the $\mathrm{Fe}^{3+}$ content is carried out photometrically according to the known method [19].

To study the change in the size of colloidal particles over time, the experiment was carried out similarly, but the treated water was not filtered, and the optical density was immediately determined using a photoelectric colorimeter KFK2-UHL42.

To study the dispersed composition of the precipitates obtained, the wastewater was sonicated, sedimented until the solid phase precipitated, the liquid was decanted, and the sediment was transferred to a glass slide and dried using a West EHF 2001WR fan heater. Dried precipitates were investigated using a Carl Zeiss NU-2 optical microscope, which was equipped with a Canon IXUS 90IS digital camera for micrographs.

The size of suspended particles was determined turbidimetrically also [20].

Preliminary studies have shown that iron is partially contained in sulfide form in the form of colloidal particles. Particles do not settle for a long time, do not coagulate arbitrarily and pass freely through the filter.

To study the possibility of additional treatment of iron-containing wastewater by ultrasonic coagulation of the pollutant, which laboratory setup is shown in Figure 1, has been used. The main element of the installation is an ultrasonic generator and a transducer in a set of UZDN-2T. Magnetostrictive transducer, which was cooled, with a conical 
concentrator and a submersible working tool. The ultrasonic generator allows you to work at a frequency of 22 and $44 \mathrm{kHz}$ and change the intensity of the treatment $0-100 \mathrm{~W} / \mathrm{cm}^{3}$ with a processed volume of up to $50 \mathrm{ml}$.

In the experiments, a processing intensity of $20-100 \mathrm{~W} / \mathrm{cm}^{3}$ was used; processing time was $5-45$ minutes.

After treatment, the wastewater was poured from a ceramic beaker into a flask, filtered and examined for the content of iron compounds. The precipitates obtained are firmly held in the pores of the filter and are not valuable.

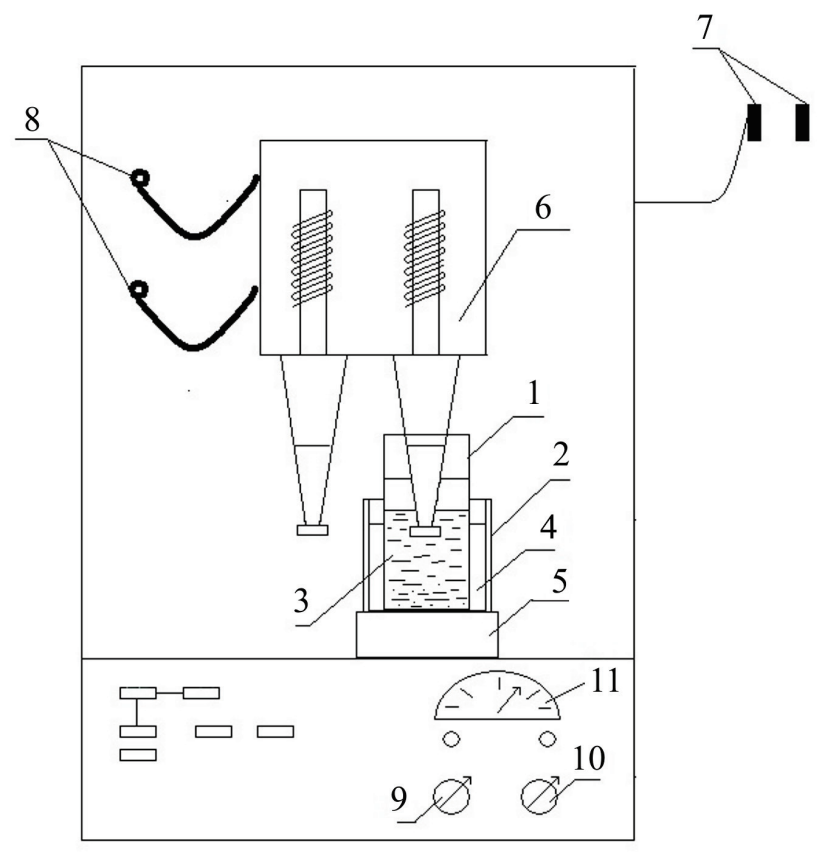

Fig. 1. Scheme of the laboratory setup: 1 - reaction vessel; 2 - cooling capacity; 3 - treated water; 4 - cooling water; 5 - soundproof substrate; 6 - block magnetostrictive emitters; 7 - block connection of emitters at 22 and $44 \mathrm{kHz} ; 8$ - input and output of cooling water block emitters; 9 - power controller; 10 - resonance regulator; 11 - milliammeter.

\section{Results and discussion}

As a result of the experiment, it is found that changing the frequency of ultrasound does not significantly affect the coagulation process. The best results are achieved with a maximum processing intensity of $100 \mathrm{~W} / \mathrm{cm}^{3}$ (Fig. 2-4).

As the results of the experiments show, a decrease in the sound flux density does not affect the speed of the coagulation process, but significantly affects the size of the resulting final particles, as well as the degree of purification, which varies proportionally. The maximum degree of purification obtained is $63 \%$ and is achieved 20 minutes after the start of sample processing.

With the continuation of the process over the next 25 minutes, the formed particles are destroyed, and the iron compounds again become colloidal. In this case, the degree of purification is reduced to $0 \%$.

To explain this phenomenon, an attempt was made to trace the dynamics of changes in particle size. For this, the microscopic and turbidimetric methods were used.

Microphotographs of precipitations obtained by ultrasonic treatment of wastewater are 
shown in Figure 4.

Particle size studies confirm the assumption of the destruction of coagulated particles during prolonged treatment [21].



Fig. 2. The dependence of the concentration of residual iron in the treated water $\left(C_{\mathrm{Fe}}\right)$ from the processing time $(\tau)$.

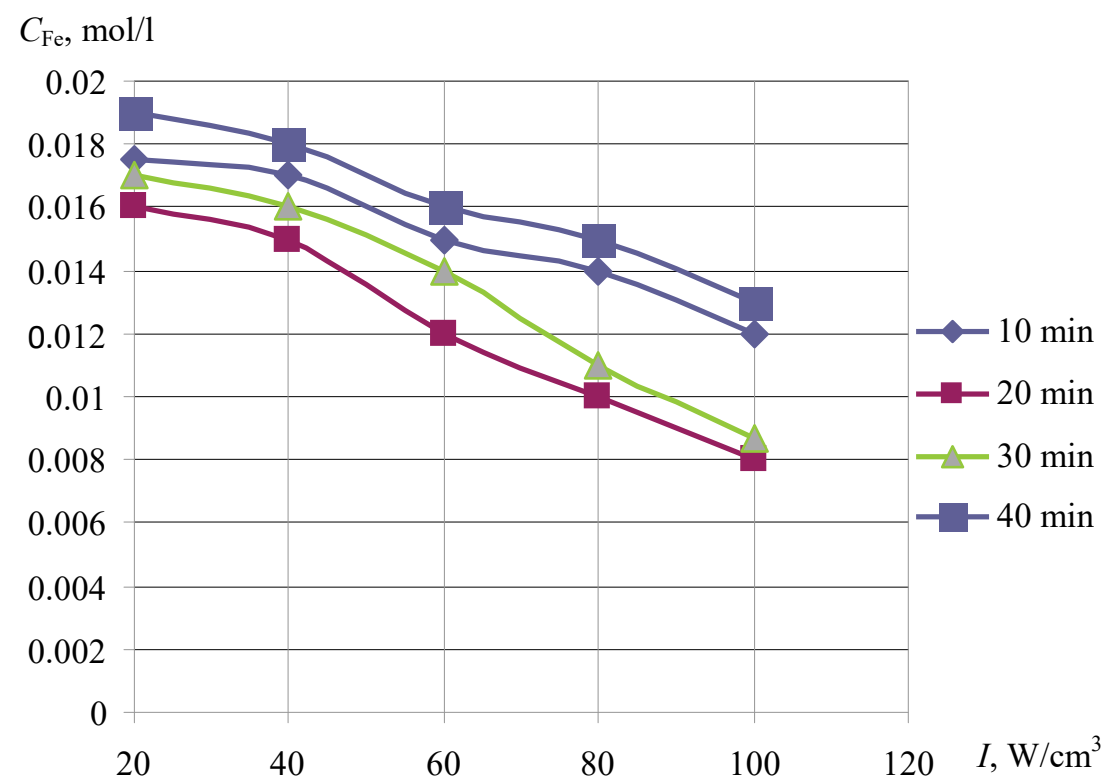

Fig. 3. The dependence of the concentration of residual iron in the treated water $\left(C_{\mathrm{Fe}}\right)$ from the processing intensity $(I)$. 


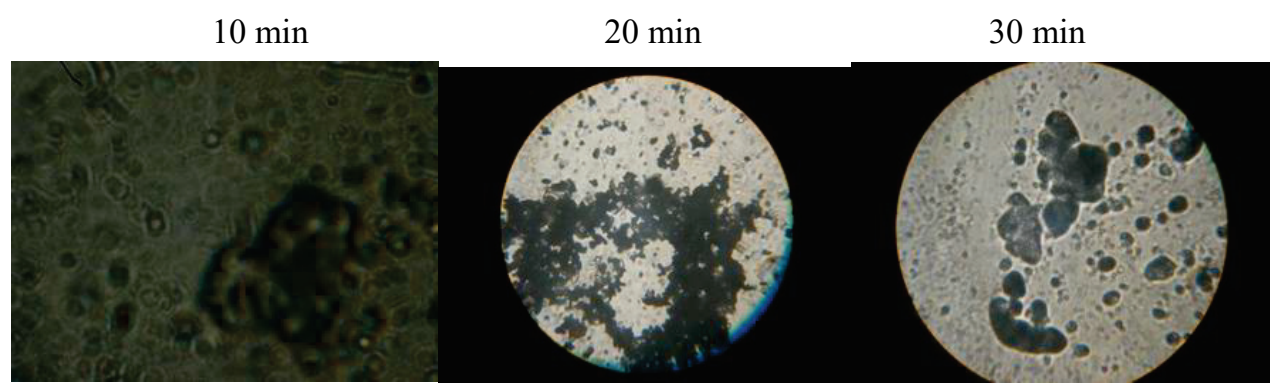

processing intensity $100 \mathrm{~W} / \mathrm{cm}^{3}$

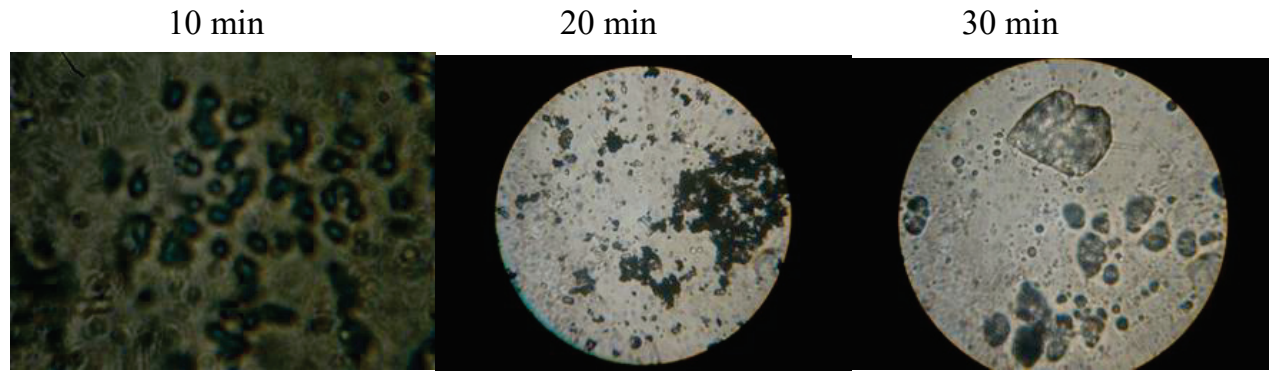

processing intensity $50 \mathrm{~W} / \mathrm{cm}^{3}$

Fig. 4. Microphotographs of precipitations which obtained by ultrasonic treatment of wastewater.

Studies have been used to develop the principal technological scheme iron after treatment process wastewater, which is shown in Figure 5.

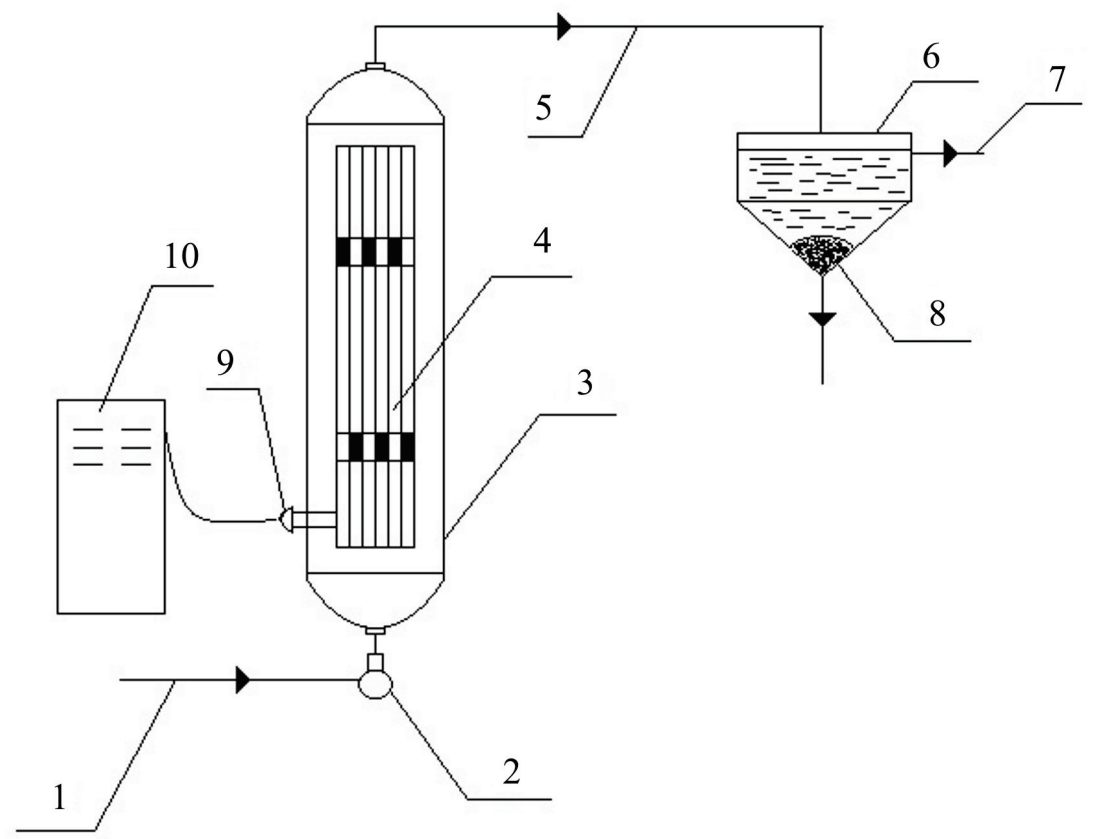

Fig. 5. Principal technological scheme of the purification of wastewater from colloidal impurities of iron compounds: 1 - supply of wastewater; 2 - pressure pump; 3 - ultrasound column; 4 magnetostrictive converter; 5 - treated water; 6 - sump; 7 - clarified water; 8 - sediment for unloading; 9 - cable entry; 10 - generator of ultrasonic vibrations. 
The main apparatus of the scheme is an ultrasonic column 3. Ultrasonic vibrations are excited in the treated wastewater by a magnetostrictive transducer 4 , fed from an ultrasonic vibrations generator 10 through a cable, supplied through a cable entry 9.

The treated wastewater is supplied to the ultrasonic column by a pressure pump 2 and processed by ultrasound with a frequency of $22 \mathrm{kHz}$ and an intensity of $100 \mathrm{~W} / \mathrm{cm}^{3}$ for 20 minutes. These parameters were chosen as the main ones as a result of studies conducted by us earlier.

After ultrasonic treatment, wastewater which containing coagulated precipitations are sent to a settling tank 6 , where they are finally freed from the solid phase. In Figure 5 shows an embodiment of a process flow diagram for continuous cleaning. In this case, water continuously passes through the column, crossing the ultrasonic field, and the colloidal particles coagulate at a total residence time of 20 minutes in the column. There are also options for technological schemes of periodic action and schemes with water recirculation.

\section{Conclusions}

Ultrasonic treatment is an effective method for coagulation fine precipitations of the wastewater. It was established that the intensity of ultrasonic treatment was not affect the coagulation rate, however, it affects the degree of purification, which varies in direct proportion. This is due to the fact that the particle sizes in the treated slurry are increased. The dependence of the degree of purification on the processing time is extremal. The maximum degree of purification is achieved 20 minutes after the start of wastewater treatment. When continuing the process over the next 25 minutes, the agglomerates, which formed, is destroyed, and iron compounds are moving back into colloidal condition. The results were the basis for the development of a technological scheme for wastewater treatment.

\section{References}

1. M. Vepsalainen, M. Sillanpaa, Advanced Water Treatment (Elsevier, 2020)

2. K. Rehman et al., J. Cell. Biochem., 119, 157-184 (2018)

3. V. Abramov et al., J. Machine Constr. Maint. Problemy Eksploatacji (2019)

4. P.C. Sangave, A.B. Pandit Ultrason. Sonochem., 11, 197-203 (2004)

5. L. Frolova, A. Pivovarov, E. Tsepich, J. Chem. Technol. Metallurgy, 51, 163-167 (2016)

6. S.K. Khanal et al., Crit. Rev. Envir. Scien. Technol., 37, 277-313 (2007)

7. L.A. Frolova, A.A. Pivovarov, High Energy Chem., 49, 10-15 (2015)

8. L. Frolova, A. Pivovarov, E. Tsepich, Nanophys., Nanophot., Surf. Studies, Appl. (Springer, Cham, 2016)

9. Z. Wei, F.A. Villamena, L.K. Weavers, Envir. Scien. \& Technol. 51, 3410-3417 (2017)

10. S.G. Babu, M. Ashokkumar, B. Neppolian, Top. Curr. Chem. 374, 75 (2016)

11. J.H. Gibson et al., Water research, 43, 2251-2259 (2009)

12. Y. Li et al., J. Hazard. Mat., 244, 403-411 (2013)

13. R.H. Jawale, A. Tandale, P.R. Gogate, Ultrason. Sonochem., 38, 402-409, (2017)

14. L. Borea et al., Ultrason., 83, 42-47, (2018)

15. L.A. Frolova, N.N. Shapa, Metallurg. Min. Ind., 3, 287 (2011)

16. P.B. Subhedar et al., Ultrason. Sonochem., 27, 530-535 (2015)

17. V.V.Goncharuk, V.V. Malyarenko, V.A. Yaremenko, Khim. Tekhnol. Vody, 26, 275286 (2004) 
18. Yu. Yu. Lur'e, A.I. Rybnikova, Khimicheskij analiz proizvodstvennykh stochnykh vod (Moskva,: Khimiya, 1974)

19. V.B. Aleskovskij, Fiziko-khimicheskie metody analiza (Lenegrad: Khimiya, 1988)

20. Yu.G. Frolov, Laboratornye raboty i zadachi po kolloidnoj khimii (Moskva: Khimiya, 1986)

21. A.V. Mamchenko, I.I. Mekhiko i dr. Khim. Tekhnol. Vody, 28, 342-355 (2006) 